\title{
Corporate Accelerators As Recent Form Of Startup Engagement: The What, The Why, And The How
}

Dominik K. Kanbach, HHL Leipzig Graduate School of Management, Germany

Stephan Stubner, Ph.D., HHL Leipzig Graduate School of Management, Germany

\begin{abstract}
An increasing number of established companies have recently started to launch corporate accelerator programs to engage with entrepreneurial startups, making this a worldwide, cross-industrial phenomenon. Nevertheless, there is a lack of understanding of the various objectives and approaches adopted by companies. This article examines 13 indepth case studies of corporate accelerator programs and is the first to empirically derive and discuss a typology for corporate accelerators, assessing objectives and design configurations. Thereby, the article contributes to the emerging discussion about corporate accelerators in corporate entrepreneurship literature. Moreover, the findings provide corporate managers with an understanding of corporate accelerators and guidance for how to make design choices for startup engagement programs.
\end{abstract}

Keywords: Corporate Accelerator; Startup Engagement; Corporate Entrepreneurship

\section{INTRODUCTION}

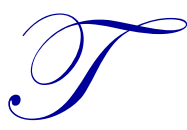

here has been a recent surge of corporate accelerator programs worldwide. Especially since the beginning of the 2010s, an increasing number of companies have established these programs to internalize the opportunities presented by external startups (Weiblen \& Chesbrough, 2015). By early 2016, the "Corporate Accelerator Database" listed more than 65 active programs in 25 countries (The Corporate Accelerator Database, 2016), whereas other sources estimate there to be more than 120 programs (Desai, 2016).

In contrast to the existing corporate venture capital initiatives, corporate accelerators not only provide direct and indirect financial support to startups, but also aim to achieve additional objectives with more comprehensive startup support models. Self-descriptions of corporate accelerator programs provide a variety of objectives, including endeavors to "support entrepreneurs and startups" (ProSiebenSat.1, 2016), to "develop new business ideas and bring them to life" (E.On :agile Accelerator, 2016), and to "support digital transformation" (Techstars Metro Accelerator, 2016).

Companies launching corporate accelerators are from diverse industries, for instance, Walt Disney and Spring in the USA, Citigroup and Samsung in Israel, and METRO and Bayer in Germany. Several corporate accelerator programs have multiple international locations, such as Microsoft's accelerator program in seven cities in Europe, Asia, North America, and the Middle East, and Google's in three countries in Latin America. As such, corporate accelerators are a global, cross-industrial phenomenon.

It is understood that corporate accelerators are typically time-limited programs with a standard duration of roughly three months that conduct a selective admission of a cohort of startups on a specific date. Furthermore, they provide various services, such as office space, mentoring, training, and networking opportunities, in addition to investment capital for startups (Cohen, 2013; Hallen, Bingham, \& Cohen, 2014; Hochberg, 2015; Hoffmann \& RadojevichKelley, 2012; Malek, Maine, \& McCarthy, 2014). Apart from this basic understanding, however, there is a lack of common understanding of what comprises a corporate accelerator. 
Neither practical nor academic studies offer companies guidance for how to establish a corporate accelerator. More importantly, given the variety of objectives for corporate accelerator programs, different design configurations, such as the organizational integration of the program into the parent company or equity involvement in the startups, might be necessary to foster the specific objectives of an organization.

This article assesses these two elements of objectives and configurational choices, and empirically derives a typology for different corporate accelerator programs. Based on a sample of 34 recent interviews with managers of corporate accelerators and participating startups, we analyze 13 in-depth case studies of corporate accelerator programs. As a result, we identify four specific types of corporate accelerators and show that the typical configurations throughout eight categories differ according to the primary objective of the program.

\section{LITERATURE REVIEW}

Existing literature on accelerator programs only provides a limited and high-level understanding. Most studies address the non-corporate context, such as independent accelerator programs (e.g., Y Combinator, USA) (Hoffmann \& Radojevich-Kelley, 2012; Kim \& Wagman, 2014) or public accelerator programs (e.g., MaRS Accelerator, Canada) (Malek et al., 2014). Only three studies in peer-reviewed journals specifically refer to corporate accelerators (Hochberg, 2015; Kohler, 2016; Weiblen \& Chesbrough, 2015).

In contrast to the anecdotal evidence outlined in our introduction, two studies claim that corporations typically have rather uniform objectives for their corporate accelerator activities, namely to insource external innovation and to stimulate and achieve corporate innovation through interaction with entrepreneurial startups. Simultaneously, these studies highlight a variety of design configurations for existing accelerator programs (Hochberg, 2015; Weiblen \& Chesbrough, 2015). Only one study highlights additional strategic objectives of corporate accelerators, such as the rejuvenation of corporate culture and talent attraction (Kohler, 2016). However, these objectives are not linked to specific program configurations.

An initial categorization of these configurations simply provides high-level design options. Companies must decide whether to build an accelerator program independently or outsource the activity to an external partner like TechStars. Alternatively, companies can partner with other companies to build a joint accelerator or join an existing accelerator as an additional partner (Hochberg, 2015). This categorization offers initial guidance, but lacks further conceptualization regarding specific company objectives and subsequent design choices. For example, further dimensions of the design choices, such as equity involvement, operational proximity, or organizational integration, are not addressed.

One existing study postulates a 4P approach, proposition, process, people, and presence, for the development of corporate accelerators (Kohler, 2016). While this framework is an important addition to understanding corporate accelerators, the interdependencies of the various configurations of those dimensions are not considered.

Thus, the existing knowledge of corporate accelerators provides a foundation for an elaborate discussion, but only a limited orientation for practitioners and insufficient guidance for the clear configuration of a corporate accelerator.

\section{ANALYSIS APPROACH}

\subsection{Methodology}

We follow an inductive research approach based on multiple case studies to achieve generalizable results (Eisenhardt, 1989). First, we analyzed each case to establish an understanding of the individual corporate accelerator. Then, we compared the cases to identify their commonalities and differences. We completed this iterative data analysis process when four specific types of corporate accelerators were clearly differentiated. Through this approach, we followed extant publications in the field of corporate entrepreneurship research (Malek et al., 2014; Weiblen \& Chesbrough, 2015). According to past research with a case study approach, three to five in-depth case studies are an acceptable number for adequate results (Eisenhardt, 1989; Hoffmann \& Radojevich-Kelley, 2012). 


\subsection{Sample and Data Collection}

Our sample consists of 13 case studies selected according to a structured approach. We focus on corporate accelerator programs that fulfill the following criteria: (1) sponsorship by one established company with its main business not being investment in startups, (2) the location of the accelerator in Germany, and (3) ongoing activity with at least one employee working full-time for the program. With the sponsorship of one established company only, we purposely excluded a small number of programs that are managed jointly by several established companies. Public organizations occasionally offer additional support to these programs, making the investigation of the objectives of and connections to specific companies more complex. Thus, we excluded these accelerators from our analysis. We focus on corporate accelerator programs in Germany due to our access to program managers and the strong presence of corporate accelerators in this country. According to database information, the second largest number of corporate accelerator programs worldwide is located in Germany. Furthermore, we exclude regional differences within our typology by including only one country in our sample. We also focus on active programs with at least one employee working fulltime for the program for data availability and access to program managers.

We identified 13 corporate accelerator programs that meet these criteria and contacted them via email or telephone to request an interview for our study. Additionally, startup companies that participated in these corporate accelerator programs were identified through the corporate accelerator websites and we asked them to participate in our study as a matched-pair triangulation. As a result, we conducted interviews with the founders and co-founders who currently or recently participated in one of the identified corporate accelerator programs. Considering the two relevant perspectives of the program, namely the corporation and the startup, allows for a more holistic view of accelerator programs and also reduces bias.

In total, our sample consists of 34 semi-structured interviews that were conducted between July and September 2015 and in February 2016. Of the 31 interviews conducted on the telephone or in person, 29 were recorded and transcribed shortly after the interviews occurred following the guidelines of Dresing and Pehl (2011). We relied on written notes for two interviews as the interviewees requested we not record the exchange. An additional three interviewees preferred to answer our questions in written form. Based on the publicly available data and the interviews conducted, a case study was compiled for each of the 13 corporate accelerator programs. Therefore, our sample covers all programs that fulfill the definition criteria. Of these, 12 cases are based on interview data and publicly available information and one is based on publicly available information only.

Table 1. Sample of corporate accelerators

\begin{tabular}{l|l|c|c}
\hline \multicolumn{1}{c|}{ Parent Company } & \multicolumn{1}{c|}{ Corporate accelerator } & Location & Founded \\
\hline Allianz SE & Allianz Digital Accelerator & Munich & 2013 \\
\hline Axel Springer SE & Axel Springer Plug\&Play Accelerator & Berlin & 2013 \\
\hline Bayer AG & Grants4Apps Accelerator & Berlin & 2013 \\
\hline Deutsche Telekom AG & hub:raum Accelerator & Berlin & 2012 \\
\hline Deutsche Bahn AG & DB Accelerator & Berlin & 2015 \\
\hline E.ON SE & :agile accelerator & Dusseldorf / Berlin & 2013 \\
\hline Immobilien Scout GmbH & YOU IS NOW Accelerator & Berlin & 2013 \\
\hline MediaSaturn Holding & SpaceLab Accelerator & Munich & 2015 \\
\hline Merck AG & Merck Accelerator & Darmstadt & 2015 \\
\hline METRO AG & Techstars Metro Accelerator & Berlin & 2015 \\
\hline Microsoft Corporation & Microsoft Ventures Accelerator & Berlin & 2013 \\
\hline ProSiebenSat.1 Media SE & ProSiebenSat.1 Accelerator & Berlin & 2013 \\
\hline Telefónica, S.A. & Wayra Accelerator & Munich & 2012 \\
\hline
\end{tabular}

\section{RESULTS OF EMPIRICAL ANALYSIS}

From our empirical analysis of the 13 case studies of corporate accelerators, we derive two complementary sets of results. First, we identify different objectives of corporate accelerator programs and the various categories that companies must consider when designing the configuration of a corporate accelerator. In total, our results identify two 
configurational dimensions, specifically program focus and program organization, resulting in eight different categories as presented in Figure 1.

Figure 1. Corporate accelerator differentiation dimensions

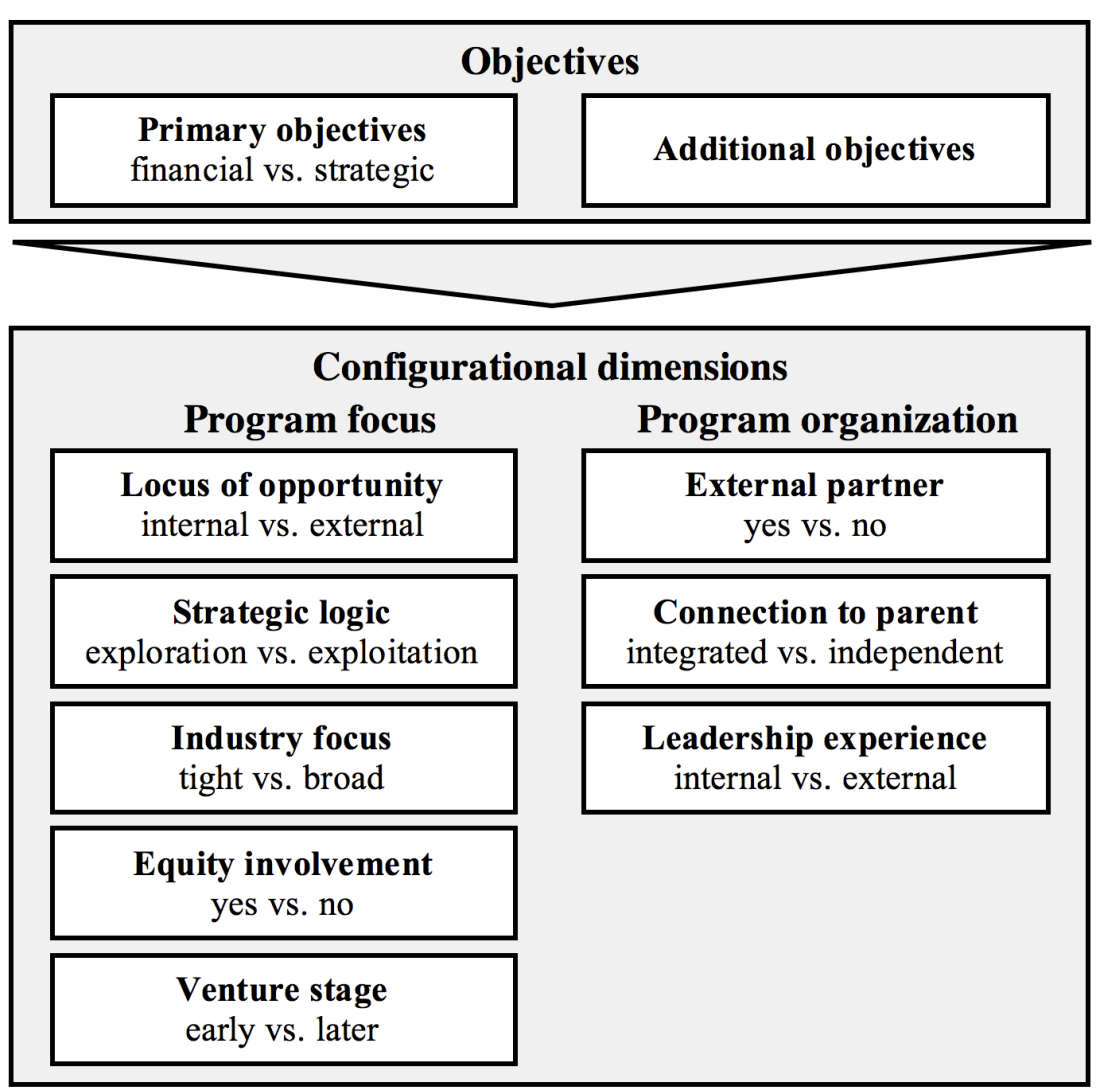

Second, building on these eight categories and the analysis of the primary objectives for corporate accelerators, we deduct four archetypes of corporate accelerators: (1) listening post, (2) value chain investor, (3) test laboratory, and (4) unicorn hunter. Our results also show the design choices with which these archetypical corporate accelerators are typically associated. This categorization provides a comprehensive overview of the current status of the corporate accelerator landscape and indications for their suitable setup based on the main objective of the program.

As the basis for the deduction of these four archetypical corporate accelerator types, the next sections discuss the two elements of corporate accelerator objectives and configurations.

\subsection{Corporate Accelerator Objectives}

The case analysis reveals a variety of objectives for corporate accelerator programs with varying priority. Therefore, we identify the primary objectives that provide the dominant program rationale as well as additional objectives that supplement the overall program rationale.

\subsubsection{Primary Objectives}

The primary objectives can be categorized as being either financial or strategic. In comparison to financial objectives, strategic objectives are multifaceted, providing a more concrete understanding of the generally acknowledged objective of supporting corporate innovation. 


\subsubsection{Financial Objectives}

The practice of generating financial returns by using corporate accelerator programs is rooted in the rationale that startups increase in value through participation in the program, and the parent company benefits financially. Based on the provision of coaching, mentoring, and training as well as an environment conducive to development, the startups improve and therefore increase the value of the parent company's shares in the startup. In the corporate accelerator programs in our sample, financial objectives are always combined with additional non-financial objectives. However, financial objectives are not always of the utmost importance. In this case, financial returns are frequently defined as a necessary condition for program sustainability.

\subsubsection{Strategic Objectives}

There are diverse strategic objectives of corporate accelerator programs, and we identify three primary strategic objectives that extend the existing understanding of corporate accelerator objectives regarding insourcing innovation.

Firstly, gaining an understanding of current market developments, trends, and technologies is one strategic objective of corporate accelerators. For the parent companies in our sample, the exchange with entrepreneurial startups in a respective market is valuable since it allows the company to identify developments and recent and upcoming trends. The accelerator program in this context is a precursor for the internal innovation or research and development departments. Due to the startups usually working closely together with representatives of the parent company, exchanges about these topics are intensive and frequent. This objective is also described as a way to ascertain emerging technologies.

Secondly, in addition to understanding trends and technologies in the market, the further development and integration of the products and services from the startups is a strategic objective. The products and services of the startups are expected to improve while in the accelerator, mainly by leveraging the competencies, resources, and networks of the parent company and potential external experts. After the program, the startup's integration into the value chain of the company is desired. The targeted integration can vary, including the marketing of products through the parent company's sales channels, the use of the product or service by the parent company, the increase of the parent company's shares in the startup, or a full take-over and integration of the startup into the parent company.

Thirdly, another strategic objective involves evaluating innovative products and services that have the potential to disrupt the current business of the parent company. The main rationale is that constraints stipulated by corporate regulations often prevent the testing and launching of new and potentially disruptive business models. Therefore, the corporate accelerator is designed as a protected environment that provides the resources and expertise required for development and testing without corporate interference.

\subsubsection{Additional Objectives}

There are two additional strategic objectives. First, corporate accelerator programs strive to create a spirit of entrepreneurship within the established organization. Knowledge about entrepreneurial ways of working and cultural aspects is exchanged through the interaction of the startups with the employees from various departments, such as marketing, product development, corporate development, research and development, or other functions of the corporate parent. From an organizational perspective, corporate accelerators often report to these departments and frequently have access to top management, which further facilitates the creation of an entrepreneurial spirit within the established company.

Second, corporate accelerator programs impact the marketing and public relations internal and external communication activities targeted at creating an image of being an innovative, agile, and flexible organization open to new developments in the market and industry. Parent companies frequently mention their corporate accelerator programs in external communication, such as press releases or annual reports, and the corporate accelerator programs use social media for publicity. This communication also positions the company as an attractive employer and thereby 
aims to attract young talent. Furthermore, positioning the parent company within the startup ecosystem as an active investor is also a public relations objective.

\subsection{Corporate Accelerator Configurations}

In addition to these various objectives, we identify two dimensions of corporate accelerator configurations: program focus and program organization. Altogether, these dimensions include eight categories.

\subsubsection{Program Focus}

The first dimension, program focus, includes five of the eight categories that comprise the corporate accelerator configuration.

\subsubsection{Locus of Opportunity}

Corporate accelerators differ in their program focus in terms of locus of opportunity. Where several programs focus on external startups exclusively, other programs also target internal business ideas and startups. However, we do not find a corporate accelerator program that focuses on internal business ideas exclusively.

\subsubsection{Strategic Logic}

Regarding strategic logic following March (1991), we find a few differences among corporate accelerators. Exploration-oriented programs focus on understanding market trends and developments as well as identifying the responsible entrepreneurial startups. Exploitation-oriented programs use existing parent company competencies to improve startup development. Although our analysis reveals that most programs follow exploration and exploitation logic simultaneously, usually one form of logic dominates.

\subsubsection{Industry Focus}

Our analysis reveals a variety in the industry focus of the startups and in the operational proximity to the parent company. The heterogeneity in this dimension ranges from programs that clearly focus on startups within a specific industry relevant to the parent company to programs that have a very broad or no focus and admit startups with diverse industrial backgrounds.

\subsubsection{Equity Involvement}

We find programs with and without equity involvement in the startups. Equity involvement is usually between five and nine percent, which is transferred either directly by giving shares to the investor or in the form of a convertible loan that converts into equity at the next financing round of the startup.

\subsubsection{Venture Stage}

We find the venture stage of the startups also differs across corporate accelerators. Several programs admit startups that are in the idea stage and may not even be registered companies, some that are in the prototype stage, and some in later stages that have business with customers and generate revenue.

\subsubsection{Program Organization}

The second dimension, program organization, includes the remaining three categories that comprise the corporate accelerator configuration. 


\subsubsection{External Partner}

There are corporate accelerator programs that are initiated and run internally, and others that contract an external partner. TechStars and Plug\&Play Techcenter are such external partners, and are also the two most frequent global partners. ${ }^{1}$ Selecting an external partner is often due to the launch and execution of a corporate accelerator program being complex and the parent company lacking the required capabilities.

\subsubsection{Connection to Parent}

Corporate accelerators are either integrated within the parent company organization as part of a specific business unit, such as digital or online business, or a specific department, such as innovation management, corporate strategy, or product development. This integration into one specific department also determines the reporting line of the accelerator management team, which usually reflects the objectives of the programs. As an alternative to integration into the parent company, the corporate accelerator can be launched as an independent organization in the form of an independent legal entity that usually acts as a $100 \%$ subsidiary of the parent company, ensuring a higher level of independence.

\subsubsection{Leadership Experience}

The management of the corporate accelerator can either be the responsibility of someone with work experience in the parent company or of someone hired externally. We find examples of heads of corporate accelerators with more than 15 years of experience within the parent company and a large network of internal contacts, and others with experience in the startup ecosystem and a network of relevant external stakeholders, such as investors.

\section{CORPORATE ACCELERATOR TYPOLOGY: FOUR DISTINCT TYPES}

Based on our empirical analysis, we identify four distinct types of corporate accelerators specific to the primary objectives and the program configuration. Three types, (1) listening post, (2) value chain investor, and (3) test laboratory, are based on mainly strategic rationale. The fourth, (4) unicorn hunter, is based on mainly financial rationale, and, therefore, applies the business model of an independent accelerator within the corporate context.

\subsection{Listening Post}

The listening post corporate accelerator has a purely strategic orientation without any direct financial objectives. The main rationale for running this accelerator is to understand the overall developments and trends in a respective market or industry and initiate cooperation with startups in these areas. This objective is frequently described as the creation of a window into the new technologies and developments that might become relevant for the parent company or might disrupt the industry.

A major differentiating factor for this type of corporate accelerator is that there is no equity involvement of the parent company in the startups, which underlines its purely strategic rationale. Instead, the listening post corporate accelerator follows a cooperative approach, which also involves less steering complexity for the parent company.

The strategic rationale is also reflected in the focus of the programs, as the listening post corporate accelerators with an exclusive focus on external startups are exploration-oriented towards external developments and recent and upcoming trends. In this explorative context, the programs focus on business areas that are mainly adjacent to the parent company, but not in very strict sense. Therefore, startups that have promising ideas in fields that are not a source of revenue for the parent company are frequently admitted to these programs. As the exchange with the startups and their ideas and technologies are of high relevance to the program, startups that are not yet legally founded but have promising ideas can regularly be admitted to these programs. The venture level of the startups, however, seems

\footnotetext{
${ }^{1}$ The corporate accelerator database (www.corporate-accelerators.net) lists 22 out of 67 corporate accelerator programs with an external partner (as of March 12,2016), thereof nine TechStars and three Plug\&Play Techcenter.

Copyright by author(s); $\underline{\text { CC-BY }} \quad 1767$

The Clute Institute
} 
to depend on the industrial focus. In the field of complex technologies, for example, startups must have passed the idea stage to gain admission. Frequently, however, programs of this type are open to startups in very early stages.

The importance of strong collaboration and proximity to the startups is also reflected in the organization of these programs. Listening post corporate accelerators are integrated into the parent company organization and not established as independent legal entities.

The You Is Now Startup Accelerator by the Scout24 portals is a listening post corporate accelerator. The program provides startups with a seed investment of 15,000 Euro without an exchange for equity. Additionally, co-working space in Berlin, internal and external mentoring, and special training sessions, such as pitch training, are offered. The program occurs twice a year and focuses on early-stage web-technology startups and entrepreneurial teams with promising ideas related to real estate. It is one of the longest lasting active programs in Germany, and concludes with a demo-day in Berlin to which renowned international speakers from the fields of startups and venture capital are invited.

The Microsoft Ventures Accelerator in Berlin was launched in the autumn of 2013 as part of Microsoft's global startup community with accelerators in seven cities worldwide. The four-month program offers technology startups with diverse industrial backgrounds mentorship, training, technical support, and networking opportunities with Microsoft executives. Instead of investment capital, the startups are granted the use of Microsoft products to further develop their businesses. After completing the program, startups become part of the global alumni network that includes more than 400 startups.

\subsection{Value Chain Investor}

The value chain investor corporate accelerator also has a strategic orientation. The main objective is to identify and develop startups with new and innovative products and services from which the parent company can benefit somewhere along its value chain. These benefits might include the marketing of products or services through the existing distribution channels of the parent company. For example, additional products and services that complement or support, but do not necessarily replace, the parent company's existing offerings. Therefore, startups are usually active in business areas with strong linkages to the parent company's business or target similar customer groups.

Equity involvement in the startups is obligatory for value chain investor corporate accelerators to ensure access to technologies and strengthen cooperation. Usually, the objective is to maintain strong relationships with the most successful and relevant startups beyond the program's duration. This relationship might include an increase in equity shares in the startup, a full take-over, or the integration of the product or service into the parent company's offerings.

The rationale behind these programs is that during the accelerator program, the startups can take advantage of the extensive expertise of the parent company in a specific business area. For startups, using the customer base of the parent company for product tests or trials is a highly relevant practice. Finally, the startups can use the parent company's distribution channels, which frequently consist of thousands of outlets and millions of potential opportunities, to find customers. The startups are frequently in later stages than those in listening post corporate accelerator programs. Typically, they have developed a product or service, or are at least in the prototype stage, and some companies already generate revenues with their offerings.

From an organizational perspective, the value chain investor corporate accelerators are part of the corporate parent organization in departments focusing on digital businesses and innovation. Due to the more complex equity investments than the non-equity based cooperation of the listening post corporate accelerators, value chain investor corporate accelerators can also be run with the support of an external accelerator specialist.

The TechStars METRO Accelerator is an example of a value chain investor corporate accelerator with the support of an external partner. The program was initiated by METRO Group, a global retail and wholesale group, with the objective to support the development of innovative solutions for the hospitality industry by engaging with entrepreneurial startups. The program admitted its first cohort of 11 startups from five countries focusing on the digital 
transformation of hotels, restaurants, and catering companies in the autumn of 2015. The program has a duration of three months, and staff from METRO, the accelerator company TechStars, and the digital marketing agency RG/A run the program.

An additional example is the SPACELAB accelerator of the Media-Saturn-Holding GmbH, a leading German consumer electronics retailer active in 15 European countries with more than 1,000 retail outlets and online shops. The accelerator program, which launched in 2015, supports startups along the entire value chain of the parent company from logistics applications to innovative gadgets. Numerous dedicated support-partners are integrated from various fields of expertise, including advertising, financial planning, market research, business strategy, information technology, and logistics. Mentorship from the top management team is another important program feature necessary to leverage the success of the startups. Located in Munich, the program also provides office facilities, a hardware development lab, investment capital, and access to the resources of Media-Saturn.

\subsection{Test Laboratory}

The test laboratory corporate accelerator is also strategically oriented. The main rationale is to provide a protected environment for testing promising new business ideas. In contrast to all other corporate accelerator types, the test laboratory corporate accelerator does not exclusively focus on external startups. It also, and sometimes mainly, is dedicated to internal business ideas. This unique approach regarding the locus of opportunity also impacts equity involvement. Although equity involvement is obligatory in this accelerator type, two different ways of involvement in external startups can be identified. The first is applied in combination with a stronger focus on internal business ideas than on external startups. This is a selective approach that targets a small number of collaborating external startups as long-term partnerships and potential full takeovers. There is not necessarily a specific end date for startups participating in the program, but collaboration is evaluated within a specific period (e.g., three to six months), at which point whether the idea is developed or terminated is decided. The second equity involvement approach is applied if the focus is mainly on external opportunities. It focuses on a higher number of investments with minority holdings in the external startups. This approach is more typical for corporate accelerators.

Business ideas that go through the test laboratory corporate accelerator are at least minimally and often strongly related to the parent company's business or industry, as the programs are often intended to find business models for future revenue creation.

From an organizational perspective, test laboratory corporate accelerators are established as independent organizations in the form of independent legal entities acting as $100 \%$ subsidiaries of the parent company. This independence is crucial for these accelerators, as they aim to protect innovative ideas from existing corporate structures to allow for uninterrupted venture development.

One example of a test laboratory corporate accelerator is the :agile accelerator of the German utility company E.On that was initiated as an open innovation hub for energy-related business ideas from internal employees and external ventures to develop competitive business models. Three to six projects per quarter are admitted and receive funding of up to 30,000 Euro. At the end of the three-month accelerator phase, executives of E.On evaluate the ideas and decide whether to continue and invest in the startups. The program is located in two cities in Germany, Dusseldorf and Berlin. Since its beginning in 2013, the program has accelerated more than 40 startups.

Another example of a test laboratory is the Allianz Digital Accelerator launched by the global insurance company Allianz in Germany as a business incubation program. It is the innovation lab and new business building team for the Allianz Group, and focuses on building and growing InsurTech companies. This endeavor includes identifying future trends in the insurance business, asset management, and assistance services. The accelerator is a vehicle to identify and transform promising ideas into businesses. In addition to the program management of the accelerator, the team also consists of experts from various fields, such as user experience creation, graphic design, web development, digital product management, and marketing. Beyond focusing on external ideas with which entrepreneurs can apply to participate in the program, the program also concentrates specifically on internal business ideas within the Allianz Group. 


\subsection{Unicorn Hunter}

The unicorn hunter corporate accelerator is the only identified corporate accelerator type that pursues mainly financial objectives. The main objective is to earn a financial premium on the numerous minority investments in startups, which reflects the business model of independent accelerators, such as TechStars or Startup Factory. The equity involvement can be conducted in two different ways. The equity can be transferred directly in fixed terms (e.g., five percent) or in the form of a convertible loan that is converted into equity at the next financing round of the startup. Both approaches do not require an individual valuation of each of the companies before the startups enter the program. In the first approach, all companies are valued equally, as they have to agree to the fixed conditions. In the second approach, valuation is conducted with the next financing in which the convertible loan is transferred into equity.

This financial orientation also provides this corporate accelerator type with its name. The approach is designed to identify potential future unicorns, companies valued at more than $\$ 1$ billion, by investing in numerous promising companies with the objective of at least some increasing their value significantly.

In contrast to the other accelerator types, the unicorn hunter corporate accelerator follows a mainly exploitative logic as these accelerators attempt to make the companies more valuable by leveraging their assets, such as technologies, networks, competencies, or knowledge. Therefore, the startups are frequently not related to the core business of the parent company. Instead, they are chosen if they will most likely benefit from the parent company's assets. One interviewee emphasized that the accelerator program must somehow be able to help the venture become more valuable. Direct interaction with the parent company is therefore focused on transferring the capabilities to startups that help them to become more valuable companies.

From an organizational perspective, programs are run as independent legal entities. The rationale behind this design choice is that it decreases the complexity of approving the numerous investments made into external startups.

The Axel Springer Plug and Play Accelerator is one example of this accelerator type. The Berlin-based program was launched in 2013 and focuses on digital entrepreneurs of diverse industries. Three times a year, a cohort of startups is admitted into the hundred-day long program that ends with a demo-day with prestigious local and international investors. During the program, a variety of workshops, seminars, coaching, and speeches are offered to the startups to develop the startups according to their individual needs so they can become more valuable. The accelerator intends to provide an encouraging environment with office space, infrastructure, and support in which the startups can develop freely.

A further example of a unicorn hunter corporate accelerator is the program of ProSiebenSat.1 Group, one of the largest independent media corporations in Europe. The three-month program runs twice a year and is located in Berlin. The focus is on $\mathrm{B} 2 \mathrm{C}$ startups across all industries with the goal of strengthening the startups and supporting them by securing follow-on funding. In addition to 25,000 Euro of investment capital, the startups receive TV media volume with a value of 500,000 Euro to air spots on all channels of the group, provided in the form of a convertible loan valued at 175,000 Euro. The startups also receive support, mentoring, and networking opportunities within the ProSiebenSat.1 Group. 
Table 2. Corporate accelerator typology

\begin{tabular}{|c|c|c|c|c|c|}
\hline \multicolumn{2}{|c|}{ Accelerator type } & Listening Post & $\begin{array}{c}\text { Value Chain } \\
\text { Investor }\end{array}$ & Test Laboratory & Unicorn Hunter \\
\hline \multirow[b]{2}{*}{ Objective } & & Strategic & Strategic & Strategic & Financial \\
\hline & $\begin{array}{l}\text { Primary } \\
\text { objective }\end{array}$ & $\begin{array}{l}\text { Understand recent } \\
\text { trends and } \\
\text { developments in a } \\
\text { respective market and } \\
\text { initiate relationships }\end{array}$ & $\begin{array}{c}\text { Identify, develop, and } \\
\text { integrate new } \\
\text { products and services } \\
\text { into parent } \\
\text { company's value } \\
\text { chain }\end{array}$ & $\begin{array}{l}\text { Create a protected } \\
\text { environment to test } \\
\text { promising internal } \\
\text { and external } \\
\text { business ideas }\end{array}$ & $\begin{array}{l}\text { Invest in promising } \\
\text { startups, make them } \\
\text { more valuable, and } \\
\text { earn a financial } \\
\text { premium }\end{array}$ \\
\hline \multirow{5}{*}{$\begin{array}{l}\text { Program } \\
\text { focus }\end{array}$} & $\begin{array}{l}\text { Locus of } \\
\text { opportunity }\end{array}$ & External & External & Internal \& external & External \\
\hline & $\begin{array}{l}\text { Strategic } \\
\text { logic }\end{array}$ & Exploration & Exploration & Exploration & Exploitation \\
\hline & $\begin{array}{l}\text { Industry } \\
\text { focus }\end{array}$ & $\begin{array}{l}\text { Somehow related to } \\
\text { parent company }\end{array}$ & $\begin{array}{l}\text { Strongly related to } \\
\text { parent company }\end{array}$ & $\begin{array}{l}\text { At least somehow } \\
\text { related to parent } \\
\text { company }\end{array}$ & $\begin{array}{l}\text { Broad industrial } \\
\text { focus }\end{array}$ \\
\hline & $\begin{array}{c}\text { Equity } \\
\text { involvement }\end{array}$ & No & Yes & Yes & Yes \\
\hline & $\begin{array}{l}\text { Venture } \\
\text { stage }\end{array}$ & $\begin{array}{l}\text { Frequently very early } \\
\text { stage, but also later } \\
\text { stage (depending on } \\
\text { industrial focus) }\end{array}$ & $\begin{array}{l}\text { Later stage with } \\
\text { developed products } \\
\text { and customers }\end{array}$ & $\begin{array}{l}\text { Early stage, often in } \\
\text { idea status and not } \\
\text { legally founded }\end{array}$ & Early and later stage \\
\hline \multirow{3}{*}{$\begin{array}{c}\text { Program } \\
\text { organization }\end{array}$} & $\begin{array}{l}\text { External } \\
\text { partner }\end{array}$ & No & Partly & No & Partly \\
\hline & $\begin{array}{l}\text { Connection } \\
\text { to parent }\end{array}$ & Part of parent & Part of parent & $\begin{array}{c}\text { Separate legal } \\
\text { entity }\end{array}$ & Separate legal entity \\
\hline & $\begin{array}{l}\text { Leadership } \\
\text { experience }\end{array}$ & Internal / external & Internal / external & Internal & External \\
\hline \multicolumn{2}{|l|}{ Example } & $\begin{array}{c}\text { YouIsNow } \\
\text { Accelerator } \\
\text { (ImmobilienScout24); } \\
\text { Microsoft Ventures } \\
\text { Accelerator } \\
\text { (Microsoft) }\end{array}$ & $\begin{array}{c}\text { TechStars METRO } \\
\text { Accelerator } \\
\text { (METRO AG); } \\
\text { SPACELAB } \\
\text { (Media-Saturn } \\
\text { Holding) } \\
\end{array}$ & $\begin{array}{l}\text { :agile Accelerator } \\
\text { (E-On); Allianz } \\
\text { Digital Accelerator } \\
\quad \text { (Allianz SE) }\end{array}$ & $\begin{array}{c}\text { Axel Springer Plug } \\
\text { \& Play } \\
\text { (Axel Springer AG); } \\
\text { Pro7Sat.1 } \\
\text { Accelerator } \\
\text { (Pro7Sat.1) }\end{array}$ \\
\hline
\end{tabular}

\section{DISCUSSION AND IMPLICATIONS}

Our study shows that corporate accelerators are not uniform and that four distinct types of corporate accelerators exist, each of which pursues different objectives and consists of specific configurations regarding their focus and organization. As such, our study reveals that corporate accelerators exist not only for the single strategic objective of insourcing innovation, as previous studies suggest, but also for various strategic and financial reasons.

Based on our in-depth case analysis, we provide two main fields of operationalization of our findings for practitioners in established companies that plan to or already employ a corporate accelerator. First, we create a link between the objectives and design configurations, and second, we highlight the success factors for corporate accelerator programs.

\subsection{Linking Objectives and Design Configurations}

The four distinct types of corporate accelerators represent the current landscape and provide a foundation for the evaluation of existing or new accelerator activities. The primary concern for an established company is determining the main objective of the accelerator. Companies can better understand developments in a respective market, identify and potentially integrate new products or services, create a protected environment from corporate structures for internal and external entrepreneurs, or generate a financial return by investing in diverse promising startups. Determining this guides the specific configuration, as outlined and illustrated with recent examples in Table 2. The 
design choices that managers can make regarding the program focus and organization are distinct for each corporate accelerator type and are discussed in the next sections.

\subsubsection{Program Focus}

Each of the four corporate accelerator types features a unique characteristic regarding program focus. The listening post corporate accelerator is the only type that renounces equity involvement in the startups. Following transaction cost logic, equity involvement bears additional costs stemming from search and information, bargaining, and monitoring and enforcement (Weiblen \& Chesbrough, 2015). As the main objective of listening post corporate accelerators is to create an understanding of recent developments, it follows cooperation logic instead of investment logic, avoiding the additional costs from equity involvement. However, companies following this approach can make selected investments in successful or relevant startups at a later stage.

The value chain investor corporate accelerator is specific concerning the venture stage of the startups. Compared to all other types, startups in these corporate accelerators are more mature, being at least in a prototype stage, and frequently already offer their products or services on the market and generate revenue. As the objective is to identify innovative products and services for the parent company's business, startups in an idea stage are considered too undeveloped. As a result, the investment capital for startups also appears to be the highest among all types of corporate accelerators.

The test laboratory corporate accelerator has the objective of creating a protected environment for work on promising business ideas and is unique regarding its locus of opportunity. It is the only type of corporate accelerator that admits internal and external startups into the program. The priorities, however, seem to vary. Where some test laboratory corporate accelerators focus on internal business ideas, making them mainly intrapreneurship programs, others have a more balanced ratio of internal to external startups.

The unicorn hunter corporate accelerator is specific regarding its industrial focus.

Unlike the startups in the other corporate accelerator types, startups in unicorn hunter corporate accelerators are not required to have a relationship with the industry or business context of the parent company. Financial objectives dominate this type, and the program is not intended to identify and develop promising business models with future relevance for the parent company. Therefore, startups with the highest diversity of industrial backgrounds are found in these corporate accelerators.

\subsubsection{Program Organization}

The listening post and value chain investor corporate accelerators are both integrated into the parent company organization. For these programs, the strong exchange and interaction with the parent company is of high relevance for achieving objectives. The listening post corporate accelerator involves exchanges regarding developments and market trends, whereas the value chain investor corporate accelerator develops products that can be integrated into the value chain of the parent company. A strict separation from the parent company is not necessarily required in these contexts, and might also hinder the achievement of these objectives.

The test laboratory and unicorn hunter corporate accelerators, however, differ in that integration into the parent company is considered an obstacle. For the test laboratory corporate accelerator, the strict separation from the daily business of the parent company is considered a major factor for the testing of new business ideas that would not easily find a space in the existing organization. It is generally thought that the financially oriented unicorn hunter corporate accelerator requires the freedom to make investment decisions without corporate interference. This independence from the parent company also appears to be reflected in the work experience of the managing directors. In unicorn hunter corporate accelerators, management usually has external work experience, mainly within the startup ecosystem or in consulting. In all other corporate accelerator types, extensive work experience within the parent company can be identified, which reflects the greater importance of interaction with business units to achieve strategic objectives. 


\subsection{Success Factors for Corporate Accelerators}

Our case analysis sheds light on the factors that our interviewees consider as highly relevant for successful corporate accelerator programs independent of the specific accelerator type.

The aspect that is perhaps the most important is the support and commitment from the top management team. As engagements with startups in the corporate environment may be discontinued during economic downturns to cut cost, commitment from and access to the management board and top management team is highly important to ensure the sustainability of the program. This stipulation is the basis for the potential medium- and long-term payoff and value contribution beyond public relations effects. Additionally, top management support increases the credibility and acceptance of the program within the entire organization. This is also crucial for achieving the commitment and encouraging the participation of all employees within the organization.

Networking at events and startup conferences and with venture capitalists is considered a further success factor as it identifies and attracts promising startups with skilled entrepreneurial teams and excellent ideas. Therefore, the active involvement within the startup ecosystem of all members of the accelerator team is considered an important responsibility.

The accelerator team also serves as an important success factor. Across all corporate accelerator types, it is helpful to have an overall mixed team of people with company-internal and company-external work experience. Internal experience enables the use of extant networks and knowledge about corporate processes and specifics. The external experience, however, provides a more unbiased perspective and, ideally, an in-depth understanding of the startup ecosystem, which strongly deviates from the typical corporate environment.

The definition of clear objectives and the ways in which companies measure their achievements are considered further important factors in designing successful corporate accelerators. Without clear objectives, the program might develop unclear value propositions, which can diffuse activities. Clear objectives, however, require the company to have a clear measurement system in place. This element is essential as the corporate accelerator acts in an environment in which transparency about added value is highly relevant for the sustainability of the activity. This also holds true for non-financial objectives, and relevant key performance indicators should be defined to demonstrate the program's contribution.

Finally, corporate accelerator programs should be designed to deliver real value to the startups. Otherwise, the programs will be short-term and, as the startups do not benefit from the program, will attract less promising startups. Therefore, corporate accelerator programs should not only be launched for public relations reasons, or to communicate the entrepreneurial image of the parent company. However, these advantages are byproducts and can be upheld by a valuable program that delivers benefits to both the parent company and the startups.

\section{CONCLUSION}

Corporate accelerators have increased in number significantly within recent years. However, the different objectives and motives of the established companies behind these programs often remain unclear. In this article, we show that there are four common types of corporate accelerators that are unique regarding their objectives and their configurations of program focus and organization. Existing understanding refers to corporate accelerators as one potential form of engagement with entrepreneurial startups for pursuing the objective of insourcing outside innovation. Our in-depth empirical study, which is one of the most comprehensive studies in this field, significantly extends this basic understanding. Based on 13 case studies of corporate accelerators, including two-level data from both the program and startup level, our study provides a clearer picture of the different facets of the strategic objectives. Our case analysis shows that the listening post, value chain investor, and test laboratory corporate accelerators are three types, each with specific strategic objectives. Furthermore, our study reveals that the unicorn hunter corporate accelerators are used for mainly financial purposes, a concept that has not been identified previously. 
However, the recent emergence of corporate accelerators is not without criticism, and media even refers to the phenomenon as "corporate accelerator glut" (Roettger, 2013). It is furthermore argued that the current trend could encourage the launch of further programs based on the "me-too" principle. Other forms of business incubations are considered to have a lead-time of five to seven years before delivering results to the parent company (Becker \& Gassmann, 2006; Weiblen \& Chesbrough, 2015). Therefore, it remains to be seen if corporate accelerators can achieve the various strategic and financial objectives outlined in our study. This success would set the basis for corporate accelerators being an effective and long-lasting concept for the engagement of established companies with entrepreneurial startups.

With the transparency of corporate accelerators created by our extensive case analysis, however, we hope to contribute to a better understanding of the overall corporate accelerator phenomenon, set the basis for further research on the effectiveness of these programs, and provide practitioners with valuable insights for improving existing or establishing new corporate accelerator programs.

\section{ACKNOWLEDGEMENTS}

We would like to express our highest gratitude and appreciation to the 34 interview partners that supported this empirical research with their valuable time and insights.

\section{AUTHOR BIOGRAPHIES}

Dominik K. Kanbach is a Ph.D. candidate at the Dr. Ing. h.c. F. Porsche AG Chair of Strategic Management and Family Business at HHL Leipzig Graduate School of Management in Germany. He works as a strategy consultant for Stern Stewart \& Co. based in Munich, Germany. His research interest is corporate entrepreneurship with a special focus on corporate venturing activities in established companies.

Stephan Stubner is a Professor at HHL Leipzig Graduate School of Management in Germany, where he serves as the Chairman of the Dr. Ing. h.c. F. Porsche AG Chair of Strategic Management and Family Business. He has published research on strategy, family firms and entrepreneurship in numerous international journals, such as the Journal of Family Business Strategy, Schmalenbach Business Review, International Small Business Journal and the Journal of Small Business and Entrepreneurship. His current research interests are corporate entrepreneurship as well as boards and governance in entrepreneurial organizations.

\section{REFERENCES}

Becker, B., \& Gassmann, O. (2006). Gaining leverage effects from knowledge modes within corporate incubators. $R \& D$ Management, 36(1), 1-16.

Cohen, S. (2013). What Do Accelerators Do? Insights from Incubators and Angels. Innovations Accelerating Entrepreneurship, $8(3 / 4), 19-25$.

Desai, F. (2016, January 22). Innovation Formats Expand As Corporate Accelerator Launches Peak. Forbes Online. Retrieved from http://www.forbes.com/sites/falgunidesai/2016/01/22/innovation-formats-expand-as-corporate-acceleratorlaunches-peak/\#344c1b1a6b8c

Dresing, T., \& Pehl, T. (2011). Praxisbuch Transkription. Regelsysteme, Software und praktische Anleitung für qualitative ForscherInnen, 3.

Eisenhardt, K. M. (1989). Building Theories from Case Study Research. Academy of Management Review, 14(4), 532-550. E.On :agile Accelerator - All you need to know about :agile. (2016). Retrieved March, 20, 2016, from http://www.eon-agile.com

Hallen, B. L., Bingham, C. B., \& Cohen, S. (2014, January). Do Accelerators Accelerate? A Study of Venture Accelerators as a Path to Success?. In Academy of Management Proceedings (Vol. 2014, No. 1, p. 12955). Academy of Management.

Hochberg, Y. V. (2015). Accelerating Entrepreneurs and Ecosystems: The Seed Accelerator Model. In Innovation Policy and the Economy, Volume 16. University of Chicago Press.

Hoffmann, D. L., \& Radojevich-Kelley, N. (2012). Analysis of Accelerator Companies: An Exploratory Case Study of Their Programs, Processes, and Early Results. Small Business Institute Journal, 8(2), 54-70.

Kim, J.-H., \& Wagman, L. (2014). Portfolio size and information disclosure: An analysis of startup accelerators. Journal of Corporate Finance, 29, 520-534.

Kohler, T. (2016). Corporate accelerators: Building bridges between corporations and startups. Business Horizons, 59(3), 347-

Copyright by author(s); $\underline{\text { CC-BY }}$ 
357.

Malek, K., Maine, E., \& McCarthy, I. P. (2014). A typology of clean technology commercialization accelerators. Journal of Engineering and Technology Management, 32, 26-39.

March, J. G. (1991). Exploration and Exploitation in Organizational Learning. Organization Science, 2(1), 71-87.

ProSiebenSat.1 Accelerator - Frequently Asked Questions. (2016). Retrieved April 20, 2016, from https://www.p7s1accelerator.com/en/faq/

Roettger, N. (2013, December 24). Die Corporate-Accelerator-Schwemme. Gruenderszene. Retrieved from http://www.gruenderszene.de/allgemein/corporate-accelerator-schwemme

Techstars Metro Accelerator - Our startups. (2016). Retrieved February 15, 2016, from http://www.techstarsmetro.com

The Corporate Accelerator Database. (2016). Database of corporate accelerators [Data file]. Retrieved March 12, 2016, from https://corporate-accelerators.net/database/index.html

Weiblen, T., \& Chesbrough, H. W. (2015). Engaging with Startups to Enhance Corporate Innovation. California Management Review, 57(2), 66-90. 


\section{NOTES}

